Pacific Journal of Mathematic 


\section{ON A PROBLEM IN THE THEORY OF MECHANICAL QUADRATURES}

\section{PhILIP DAVIS}

1. Introduction. In the present note we study a scheme of mechanical quadratures of the form

$$
\int_{-1}^{+1} f(x) d x \sim \sum_{k=0}^{n} a_{n k} f\left(\lambda_{n k}\right)=Q_{n}(f),
$$

as applied to certain distinguished classes of analytic functions on $[-1,+1]$. The question of the convergence of $Q_{n}(f)$ to the integral in (1) has been solved completely by Pólya [4] when $f$ is selected from the class of continuous functions. There seems to be less discussion of the problem when $f$ is selected from the class of analytic functions on $[-1,+1]$ or from certain of its subclasses.

Let $B$ designate a region in the complex $z=x+i y$ plane which we shall assume contains $[-1,+1]$ in its interior. By $L^{2}(B)$ we designate the class of functions which are analytic and single valued in $B$ and are such that

$$
\iint_{B}|f|^{2} d x d y<\infty
$$

With

$$
(f, g)=\iint_{B} f \bar{g} d x d y
$$

as an inner product, and $\|f\|^{2}=(f, f)$ as a norm, the space $L^{2}(B)$ becomes a well-known and very useful Hilbert space of functions, possessing a reproducing kernel $K_{B}(z, \bar{w})$ which is generally referred to as the Bergman kernel for $B$ [1].

Let $E$ be a bounded linear functional over $L^{2}(B)$; its norm (over the conjugate space of all linear functionals) may be obtained in the following way. Let $\varphi_{n}(z)(n=0,1, \cdots)$ be a complete orthonormal system for $L^{2}(B)$. Then it may be shown that

$$
\|E\|^{2}=\sum_{n=0}^{\infty}\left|E\left(\varphi_{n}\right)\right|^{2} .
$$

This may be expressed in the alternate but equivalent form,

$$
\|E\|^{2}=E_{z} E_{w} K_{B}(z, \bar{w}),
$$

Received October 13, 1953. 
where the subscripts on the $E$ mean that the functional operation is to be carried out on the variable indicated. We have, then, for all $f \in L^{2}(B)$,

$$
|E(f)| \leq\|E\|\|f\|,
$$

with the equality sign being attained for some $f \in L^{2}(B)$. If now, the abscissas $\lambda_{n k}$ lie in the interior of $B$, and the segment $[-1,+1]$ lies in the interior of $B$, then the linear functional

$$
E_{n}(f)=\int_{-1}^{+1} f(x) d x-\sum_{k=0}^{n} a_{n k} f\left(\lambda_{n k}\right)
$$

is bounded (cf. [2]) over $L^{2}(B)$, so that we have, for all $f \in L^{2}(B)$,

$$
\left|E_{n}(f)\right| \leq\left\|E_{n}\right\|\|f\| \text {. }
$$

2. Uniform convergence. We shall say that the quadrature scheme (1) converges uniformly in $L^{2}(B)$ if, having been given an $\varepsilon>0$, there is an $n_{0}=n_{0}(\varepsilon)$ such that, for all $f \in L^{2}(B)$ and $n \geq n_{0}$, we have

$$
\int_{-1}^{+1} f(x) d x-\sum_{k=0}^{n} a_{n k} f\left(\lambda_{n k}\right) \mid \leq \varepsilon\|f\| \text {. }
$$

THEOREM 1. A necessary and sufficient condition that the quadrature scheme (1) converges uniformly in $L^{2}(B)$ is that

$$
\lim _{n \rightarrow \infty}\left\|E_{n}\right\|^{2}=\lim _{n \rightarrow \infty} E_{n z} E_{n \bar{w}} K_{B}(z, \bar{w})=0 .
$$

Proof. Suppose that (10) holds. Then given an $\varepsilon>0$ we can find an $n_{0}(\varepsilon)$ such that $\left\|E_{n}\right\| \leq \varepsilon$ for all $n \geq n_{0}(\varepsilon)$. Hence, by (6), the inequality (9) must hold. Conversely, suppose that (9) holds. For each $n$, it is possible to find a nontrivial function $f_{n}(z) \in L^{2}(B)$ such that

$$
\left|E_{n}\left(f_{n}\right)\right|=\left\|E_{n}\right\|\left\|f_{n}\right\| \text {. }
$$

By (9), given an $\varepsilon>0$ we may find an $n=n_{\llcorner}(\varepsilon)$ such that for all $n$ $\geq n_{0}(\varepsilon)$ and for all $f \in L^{2}(B)$ we have $\left|E_{n}(f)\right| \leq \varepsilon\|f\|$. Hence, in particular, for the $f_{n}$ of (11),

$$
\left\|E_{n}\right\|\left\|f_{n}\right\|=\left|E_{n}\left(f_{n}\right)\right| \leq \varepsilon\left\|f_{n}\right\| .
$$

Therefore (10) must follow.

We note that, in view of (4), the condition (10) can, in principle, be converted into a necessary and sufficient condition on the weights $a_{n k}$ and abscissas $\lambda_{n k}$. 
The following special case is of considerable interest. Let $\mathscr{E}_{\rho}, \rho>$ 1 , designate an ellipse with foci at $(-1,0)$ and $(1,0)$ and with semimajor and semiminor axes $a$ and $b$ respectively, and where $\rho$ is given by

$$
\rho=(a+b)^{2}, \quad a=(\rho+1) / 2 \rho^{1 / 2}, \quad b=(\rho-1) / 2 \rho^{1 / 2} .
$$

Observe that as $\rho \rightarrow 1, \mathscr{E}_{\rho}$ collapses to $[-1,+1]$. If $U_{n}(z)(n=0,1, \cdots)$ designates the Tschebysheff polynomials of the second kind defined by

$$
U_{n}(z)=\left(1-z^{2}\right)^{-1 / 2} \sin ((n+1) \arccos z),
$$

then it is well known that the system of polynomials

$$
\varphi_{n}(z)=2 \sqrt{\frac{n+1}{\pi}}\left(\rho^{n+1}-\rho^{-n-1}\right)^{-1 / 2} U_{n}(z) \quad(n=0,1,2, \cdots)
$$

will be complete and orthonormal over $L^{2}\left(\mathscr{E}_{p}\right)$. Thus we have:

THeOREM 2. A necessary and sufficient condition in order that the quadrature scheme (1) corverge uniformly in $L^{2}\left(\mathscr{E}_{p}\right)$ is that

$$
\operatorname{limit}_{n \rightarrow \infty} \frac{4}{\pi} \sum_{k=0}^{\infty}(k+1) \frac{\left|E_{n}\left(U_{k}\right)\right|^{2}}{\rho^{k+1}-\rho^{-k-1}}=0 .
$$

3. Interpolatory quadrature. An important class of quadrature schemes is formed by those which are of interpolatory type. For such quadratures we have

$$
Q_{n}(f)=\int_{-1}^{+1} f(x) d x
$$

whenever $f$ is a polynomial of degree not larger than $n$. If the scheme is of interpolatory type then (16) becomes

$$
\lim _{n \rightarrow \infty} \frac{4}{\pi} \sum_{k=n+1}^{\infty}(k+1) \frac{\left|E_{n}\left(U_{k}\right)\right|^{2}}{\rho^{k+1}-\rho^{-k-1}}=0 .
$$

In view of the inequalities

$$
\rho^{-1} \cdot \rho^{-k} \leq\left(\rho^{k+1}-\rho^{-k-1}\right)^{-1} \leq\left(\rho-\rho^{-1}\right)^{-1} \rho^{-k},
$$

condition (18) is equivalent to

$$
\lim _{n \rightarrow \infty} \sum_{k=n+1}^{\infty}(k+1) \frac{\left|E_{n}\left(U_{k}\right)\right|^{2}}{\rho^{k}}=0 .
$$

If we now define 


$$
\sigma_{k}=\left\{\begin{array}{cl}
0 & (k \text { odd }), \\
\frac{2}{k+1} & (k \text { even }),
\end{array}\right.
$$

then (20) becomes

$$
\lim _{n \rightarrow \infty} \sum_{k=n+1}^{\infty}(k+1)\left(\sigma_{k}-\sum_{j=0}^{n} a_{n j} U_{k}\left(\lambda_{n j}\right)\right)^{2} \rho^{-k}=0 .
$$

The following sufficient condition for the uniform convergence in $L^{2}\left(\mathscr{E}_{\rho}\right)$ of an interpolatory quadrature scheme can now be obtained. Set

$$
M_{n}=\sum_{j=0}^{n}\left|a_{n j}\right|,
$$

and observe that for real absissas $\lambda$ in $[-1,+1]$ we have

$$
\left|U_{k}(\lambda)\right| \leq k+1 \text {. }
$$

Then, using (21) and (23), for fixed $\rho>1$ we get

$$
\begin{array}{cc}
\sum_{k=n+1}^{\infty} & (k+1)\left(\sigma_{k}-\sum_{j=0}^{\infty} a_{n j} U_{k}\left(\lambda_{n j}\right)\right)^{2} \rho^{-k} \leq \sum_{k=n+1}^{\infty}(k+1)\left(\sigma_{k}+(k+1) M_{n}\right)^{2} \rho^{-k} \\
& \leq 4 \sum_{k=n+1}^{\infty}\left((k+1) \rho^{k}\right)^{-1}+4 M_{n} \sum_{k=n+1}^{\infty}(k+1) \rho^{-k}+M_{n}{ }^{2} \sum_{k=n+1}^{\infty}(k+1)^{3} \rho^{-k} \\
& <o(1)+C_{1} M_{n} n \rho^{-n}+C_{2} M_{n}^{2} n^{3} \rho^{-n}, \quad(n \rightarrow \infty),
\end{array}
$$

where $C_{1}$ and $C_{2}$ are two positive constants which may depend upon $\rho$ but are independent of $n$. Thus, we have the following result.

Theorem 3. Let

$$
\lim _{n \rightarrow \infty} M_{n} n^{3 / 2} \rho^{-n / 2}=0 .
$$

Then an interpolatory quadrature schsme converges uniformly in $L^{2}\left(\mathscr{E}_{\rho}\right)$

Pólya [4, p. 285] has remarked that if

$$
\lim _{n \rightarrow \infty}\left(M_{n}\right)^{1 / n}=1
$$

then an interpolatory quadrature scheme converges for all functions which are analytic in the closed basic interval. Under hypothesis (27), we have

$$
M_{n}=\left(1+\varepsilon_{n}\right)^{n}, \quad \varepsilon_{n} \rightarrow 0,
$$

so that (26) holds with all $\rho>1$. Thus, under Pólya's hypothesis, we see that the convergence is also uniform in every $L^{2}\left(\mathscr{E}_{\rho}\right), \rho>1$. 
4. Newton-Cotes quadrature. We turn now to a specific quadrature scheme on $[-1,+1]$, namely, the Newton-Cotes scheme. In this scheme, we have

$$
\begin{array}{r}
Q_{n}(f)=a_{n 0} f(-1)+a_{n 1} f(-1+2 / n)+a_{n 2} f(-1+4 / n)+\cdots+a_{n n} f(1) \\
(n=1,2, \cdots),
\end{array}
$$

where the Cotes numbers $a_{n k}$ have been determined so that

$$
Q_{n}(f)=\int_{-1}^{+1} f d x
$$

holds for an arbitrary polynomial of degree $\leq n$. We have now the following estimate due to J. Ouspensky [3] (Ouspensky's basic interval is $[0,1])$ :

$$
a_{n k}=-\frac{2}{n(\log n)^{2}}\left(\begin{array}{l}
n \\
k
\end{array}\right)\left[\frac{(-1)^{k}}{k}+\frac{(-1)^{n-k}}{n-k}\right]\left(1+\eta_{n k}\right),
$$

where $\eta_{n, k} \rightarrow 0$ as $n \rightarrow \infty$ uniformly for $k=1,2, \cdots, n-1$, while

$$
a_{n 0}=a_{n n}=\frac{2}{n \log n}\left(1+\varepsilon_{n}\right), \quad \quad \varepsilon_{n} \rightarrow 0 .
$$

Thus,

$$
M_{n}=\sum_{j=0}^{\infty}\left|a_{n j}\right| \leq \frac{4\left(1+\delta_{n}\right)}{n(\log n)^{2}} \sum_{k=1}^{n-1}\left(\begin{array}{l}
n \\
k
\end{array}\right)+\frac{4}{n \log n}\left(1+\varepsilon_{n}\right),
$$

where we have written $\eta_{n k}<\delta_{n}(k=1,2, \cdots, n-1), \delta_{n} \rightarrow 0$. Hence,

$$
M_{n} \leq \frac{4\left(1+\delta_{n}\right) 2^{n}}{n(\log n)^{2}}+\frac{4}{n \log n}\left(1+\varepsilon_{n}\right) .
$$

Condition (26) now holds with $\rho^{1 / 2}>2$. We have therefore arrived at the following result:

Theorem 4. The Newton-Cotes quadrature scheme converges uniformly in $L^{2}\left(\mathscr{E}_{\rho}\right)$ whenever $\rho>4$.

Investigation of the convergence of the Newton-Cotes quadrature scheme has an interesting history which is worth retelling here. $\mathrm{T}$. Stieltjes in 1884 first proved the convergence of the Gauss mechanical quadrature for the class of Riemann integrable functions, and in a letter to Hermite raised the question of the convergence of the NewtonCotes scheme. In $1925 \mathrm{~J}$. Ouspensky [3] arrived at the asymptotic result (29), and from the growth of Cotes numbers concluded only that the Newton-Cotes scheme is devoid of practical value. In 1933 
G. Pólya [4] showed that this scheme is not valid for all continuous functions, and, indeed, is not valid for the class of analytic functions. Pólya's counterexample, referred to the interval $[-1,+1]$ is

$$
f(w)=-\sum_{k=4}^{\infty} a^{k !} \frac{\sin k !\{(w+1) / 2\}}{\cos \pi\{(w+1) / 2\}} \quad(1 / 2<a<1),
$$

for which the Newton-Cotes scheme diverges. The functions $f(w)$ is regular in the strip

$$
|\mathscr{F}(w)|<\frac{-2 \log a}{\pi}
$$

and has a natural boundary along the sides of the strip. The widest such strip must be less than

$$
|\mathscr{F}(w)|<\frac{2 \log 2}{\pi}=0.4412 .
$$

The function (33) cannot, therefore, be continued analytically to $\mathscr{E}_{p}=4$, for which the semiminor axis is $b=.7500$. Theorem 4 , therefore, rehabilitates the Newton-Cotes quadrature scheme for functions which are regular over a sufficiently large portion of the complex plane.

\section{REFERENCES}

1. S. Bergman, The kernel function and conformal mapping, Math. Surveys, No. 5, Amer. Math. Soc., New York, 1950.

2. P. Davis, Errors of numerical approximation for analytic functions, J. Rational Mech. Anal., 2 (1953), 303-313.

3. J. Ouspensky, Sur les valeurs asymptotiques des coefficients de Cotes, Bull. Amer. Math. Soc., 31 (1925), 145-156.

4. G. Pólya, Über die Konvergenz von Quadraturverfahren, Math. Z., 37 (1933), 264-286.

National Bureau of Standards,

WASHINGTON, D. C. 


\section{PACIFIC JOURNAL OF MATHEMATICS}

\section{EDITORS}

\author{
H. L. Royden \\ Stanford University \\ Stanford, California \\ E. Hewite \\ University of Washington \\ Seattle 5 , Washington
}

\author{
R. P. Dilworth
}

California Institute of Technology Pasadena 4, California

\section{A. HorN*}

University of California

Los Angeles 24, California

\section{ASSOCIATE EDITORS}

\author{
H. BUSEMANN \\ HERBERT FEDERER \\ MARSHALL HALL
}

\author{
P. R. HALMOS \\ HEINZ HOPF \\ ALFRED HORN
}

\author{
R. D. JAMES \\ BORGE JESSEN \\ PAUL LÉVY
}

GEORGE PÓLYA

J. J. STOKER

KOSAKU YOSIDA

\section{SPONSORS}

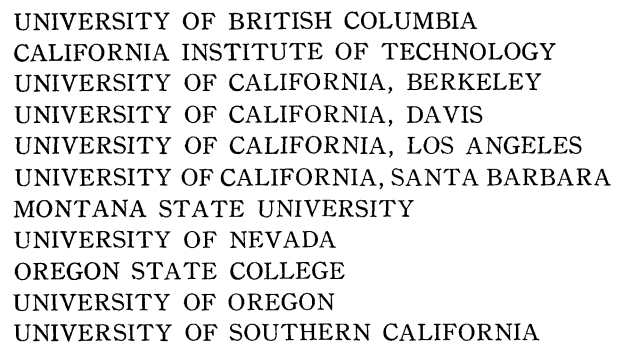

UNIVERSITY OF BRITISH COLUMBIA

CALIFORNIA INSTITUTE OF TECHNOLOGY

UNIVERSITY OF CALIFORNIA, BERKELEY

UNIVERSITY OF CALIFORNIA, DAVIS

UNIVERSITY OF CALIFORNIA, LOS ANGELES

UNIVERSITY OF CALIFORNIA, SANTA BARBARA

MONTANA STATE UNIVERSITY

UNIVERSITY OF NEVADA

OREGON STATE COLLEGE

UNIVERSITY OF OREGON

UNIVERSITY OF SOUTHERN CALIFORNIA

\author{
STANFORD RESEARCH INSTITUTE \\ STANFORD UNIVERSITY \\ UNIVERSITY OF UTAH \\ WASHINGTON STATE COLLEGE \\ UNIVERSITY OF WASHINGTON
}

AMERICAN MATHEMATICAL SOCIETY

HUGHES AIRCRAFT COMPANY SHELL DEVELOPMENT COMPANY

Mathematical papers intended for publication in the Pacific Journal of Mathematics should be typewritten (double spaced), and the author should keep a complete copy. Manuscripts may be sent to any of the editors. Manuscripts intended for the outgoing editors should be sent to their successors. All other communications to the editors should be addressed to the managing editor, Alfred Horn at the University of California Los Angeles 24, California.

50 reprints of each article are furnished free of charge; additional copies may be obtained at cost in multiples of 50 .

The Pacific Journal of Mathematics is published quarterly, in March, June, September, and December. The price per volume (4 numbers) is $\$ 12.00$; single issues, $\$ 3.50$; back numbers (Volumes $1,2,3)$ are available at $\$ 2.50$ per copy. Special price to individual faculty members of supporting institutions and to individual members of the American Mathematical Society: $\$ 4.00$ per volume; single issues, $\$ 1.25$.

Subscriptions, orders for back numbers, and changes of address should be sent to the publishers, University of California Press, Berkeley 4, California.

Printed at Kokusai Bunken Insatsusha (International Academic Printing Co., Ltd.) No. 10 1-chome Fujimi-cho, Chiyoda-ku, Tokyo, Japan.

* During the absence of E. G. Straus. 


\section{Pacific Journal of Mathematics}

\section{Vol. 5, No. $5 \quad$ BadMonth, 1955}

Henry A. Antosiewicz, A theorem on alternatives for pairs of matrice . . . . . 641

F. V. Atkinson, On second-order non-linear oscillation ............... 643

Frank Herbert Brownell, III, Fourier analysis and differentiation over real separable Hilbert spac .................................. 649

Richard Eliot Chamberlin, Remark on the averages of real function ...... 663

Philip J. Davis, On a problem in the theory of mechanical quadrature ... . . 669

Douglas Derry, On closed differentiable curves of order $n$ in $n$-spac ...... 675

Edwin E. Floyd, Boolean algebras with pathological order topologie ... . . 687

George E. Forsythe, Asymptotic lower bounds for the fundamental frequency of convex membrane ................................. 691

Israel Halperin, On the Darboux propert ................... 703

Theodore Edward Harris, On chains of infinite orde .............. 707

Peter K. Henrici, On certain series expansions involving Whittaker functions

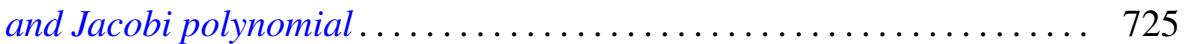

John G. Herriot, The solution of Cauchy's problem for a third-order linear hyperoblic differential equation by means of Riesz integral ......... 745

Jack Indritz, Applications of the Rayleigh Ritz method to variational

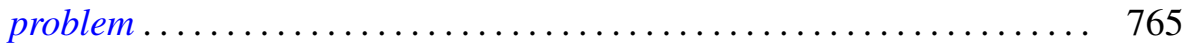

E. E. Jones, The flexure of a non-uniform bea ................. 799

Hukukane Nikaidô and Kazuo Isoda, Note on non-cooperative convex game.

Raymond Moos Redheffer and W. Wasow, On the convergence of asymptotic solutions of linear differential equation . . .

S. E. Warschawski, On a theorem of L. Lichtenstei ...........

Philip Wolfe, The strict determinateness of certain infinite game... 